\title{
Gamma radiation attenuation characteristics of polyimide composite with $\mathrm{WO}_{2}$
}

\author{
N.I. Cherkashina ${ }^{\text {a, }}$, V.I. Pavlenko ${ }^{\text {a }}$, A.V. Noskov ${ }^{\text {, }}$, V.V. Sirota ${ }^{\text {a }}$, S.V. Zaitsev ${ }^{\text {a }}$, D. \\ S. Prokhorenkov ${ }^{a}$, R.V. Sidelnikov ${ }^{\text {a }}$ \\ a Belgorod State Technological University Named After V.G. Shoukhov, Kostyukov Str., 46, Belgorod, 308012, Russia \\ ${ }^{\mathrm{b}}$ Belgorod State National Research University, Belgorod, 308015, Pobedy Str., 85, Russia
}

\section{A R T I C L E I N F O}

\section{Keywords:}

Polyimide composites

Tungsten oxide

$\gamma$-Radiation sources

Radiation resistance

Linear attenuation coefficient

Accumulation factor

\begin{abstract}
A B S T R A C T
This study presents the effect of $\gamma$-sources on polyimide composites with $\mathrm{WO}_{2}$. Experimental studies on the influence of $\gamma$-radiation on the samples are carried out using ${ }^{137} \mathrm{Cs}(\mathrm{E}=0.662 \mathrm{MeV})$ and ${ }^{60} \mathrm{Co}(\mathrm{E}=1.252 \mathrm{MeV})$ sources. The measurements are carried out both under "narrow" geometry (without considering the scattered radiation) conditions and under the conditions of a "wide" (considering the scattered radiation) beam of photon radiation. We present the distributions of the absorbed dose of $\gamma$-quanta from sources without test samples and behind test samples of a certain thickness. It is shown that the introduction of the proposed $\mathrm{WO}_{2}$ filler at $60 \mathrm{wt} \%$ more than triples the linear attenuation coefficient of $\gamma$-radiation at $\mathrm{E}=0.662 \mathrm{MeV}$ and is 2.36 times larger at $\mathrm{E}$ $=1.252 \mathrm{MeV}$ compared to the polyimide without filler. After $\gamma$-irradiation with a dose of up to $10 \mathrm{MGy}$ ( $\mathrm{E}=$ $1.152 \mathrm{MeV}$ ), no changes in the physicomechanical and electrical properties of the composites were observed. The flexural strength value before $\gamma$-irradiation was $88.52 \pm 4.47 \mathrm{MPa}$, and after $89.8 \pm 5.25 \mathrm{MPa}$. The dielectric constant of the composite before and after gamma irradiation remained unchanged $(\varepsilon=7.6)$.
\end{abstract}

\section{Introduction}

Ionizing radiation, especially $\mathrm{X}$-ray and $\gamma$-radiation, is widely used in many fields, including nuclear power, medicine, the food industry, research and so on (Rafiee et al., 2017; Dionisio et al., 2009; Pradeep Kumar et al., 2020). Ionizing radiation has a detrimental effect on human health and life, and also has a negative impact on the surrounding environment (Bakar et al., 2019). Therefore, protection of the population and the environment from radiation requires the use of a set of measures to reduce or completely prevent negative consequences. The most common protection method is the use of a protective screen (AbuAlRoos et al., 2019).

The modern development of the nuclear industry is inextricably linked with the development of new and more effective radiationprotective materials. Materials intended for protection from radiation sources at nuclear power plants must have high shielding properties with respect to both neutrons and $\gamma$-radiation. For this, the material must have a certain chemical composition based on the nuclei of light and heavy elements, and in some cases contain boron (Yastrebinsky et al., 2011; Harrison et al., 2008; Aygün, 2020; Sayyed et al., 2021a; Pavlenko et al., 2015; Dong et al., 2017). For the creation of protective screens from $\gamma$-radiation, the most widespread materials are materials containing atoms of heavy metals, often lead, with a high density (Sayyed et al., 2019; Almuqrin and Sayyed, 2021). Lead is a highly toxic material, which makes its use difficult. Heavy concrete is another promising material for radiation protection (Pomar, 2016; Bagheri et al., 2017a). However, moisture variation in concretes makes it difficult to predict radiation protection (More et al., 2021). Much research is devoted to the development of glass-based radiation shielding materials (Sayyed et al., 2021b, 2021c, 2021d; Yasmin et al., 2018; Abouhaswa and Kavaz, 2020; Bagheri and Shirmardi, 2021; Bagheri and Adeli, 2020). Composite materials based on polymers and heavy fillers are currently some of the promising materials for shielding against $\gamma$-radiation (Akman et al., 2021; Nambiar and Yeow, 2012; Pavlenko et al., 2014).

Due to the ease of molding polymer composites, they can be used in medicine to protect personnel from X-rays during radiation therapy (Tijani and Al-Hadeethi, 1088). In addition, polymer radiation-shielding composites are also used in the space industry. Benefitting from the use of a polymer binder, composites significantly reduce the mass of space technology, which makes it possible to improve the overall and mass

\footnotetext{
* Corresponding author.

E-mail addresses: cherkashina.ni@bstu.ru, natalipv13@mail.ru (N.I. Cherkashina).
} 


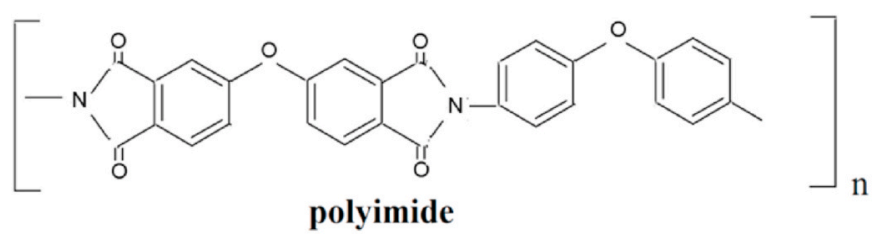

Fig. 1. Chemical structure of PI.

parameters of the spacecraft (Pavlenko and Cherkashina, 2019; Cherkashina and Pavlenko, 2018; Pavlenko et al., 2013).

The introduction of special fillers into polymers makes it possible to increase not only the radiation-protective properties of composites, but also their mechanical and electrical properties (Maruzhenko et al., 2019). Fillers, such as $\mathrm{Bi}_{2} \mathrm{O}_{3}, \mathrm{WO}_{3}, \mathrm{PbO}, \mathrm{BaTiO}_{3}$ and $\mathrm{CaWO}_{4}$, are often used to increase the radiation-protective properties of polymers (Körpınar et al., 2020; Intom et al., 2020; Bagheri et al., 2020).

It was shown that the introduction of $\mathrm{Bi}_{2} \mathrm{O}_{3}$ (44 wt\%) not only significantly improved the gamma shielding ability of poly(methyl methacrylate) composites, but also improved the microhardness to nearly seven times that of pure poly(methyl methacrylate) (Cao et al., 2020). Composites based on unsaturated polyester containing up to 30 $\mathrm{wt} \% \mathrm{PbO}$ have also been synthesized (Bagheri et al., 2018a). The gamma attenuation performance of the composites was evaluated by ${ }^{192} \mathrm{Ir},{ }^{137} \mathrm{Cs}$ and ${ }^{60} \mathrm{Co}$ gamma radiation sources. The linear and mass attenuation coefficients of the composites were found to increase with increasing $\mathrm{PbO}$ content; however, the addition of lead monoxide to the polymer weakened its thermal resistance and tensile properties. The observed negative effects could be moderated by clay nanoparticles. The properties of polymer composites are influenced not only by the type of filler, but also by factors such as the shape of the particles and their sizes, as well as the nature of their interfaces (Arbuzova and Votyakov, 2018; Abramyan et al., 2019).

In addition to the ability to attenuate ionizing radiation, materials used as protective screens must have the required radiation resistance. Radiation resistance is understood as the ability of a material to retain its properties (mechanical, electrical and optical) when exposed to ionizing radiation. The irradiation of polymers and their composites leads to rupturing of their chemical bonds and the formation of free radicals, which ultimately can lead to deformation of the material, the formation of deep cracks and even the complete destruction of the material (Ramani et al., 2003). The most important processes during polymer irradiation are crosslinking and destruction processes (Ghobashy and Abdeen, 2016; Navarro et al., 2018). The radiation resistance of polymeric materials is expressed by the dose of absorbed radiation and it differs for different polymeric materials (Klinshpont et al., 1994; Seguchi and Morita, 1999; Wündrich, 1977).

It was indicated in (Scagliusi et al., 2016) that at a dose above 100 $\mathrm{kGy}$, a significant decrease in the mechanical properties of ethylene propylene diene monomer rubbers with the predominance of chain scission with further polymer degradation was observed. Polystyrene and polyethylene terephthalate become unusable after absorption of a dose of 5 MGy (Wozniak et al., 2017). Organosilicon polymers and aromatic polyamides are slightly more stable but show significant changes in their properties after absorbing a dose of 30 MGy (Devasahayam et al., 2001). Polyimide (PI) materials have the highest radiation resistance. For PI, a twofold deterioration in mechanical properties was observed after an absorbed dose of $\sim 100$ MGy (Apel et al., 2001; Plis et al., 2019). PI is also one of the few polymers that can be used in space (Pavlenko et al., 2019).

This study presents data on the gamma attenuation characteristics of PI composites with $\mathrm{WO}_{2}$. Experimental studies on the influence of $\gamma$-radiation on the samples were carried out using ${ }^{137} \mathrm{Cs}$ and ${ }^{60} \mathrm{Co}$ sources. The physicomechanical and electrical properties of the polyimide and its composites with $\mathrm{WO}_{2}$ before and after $\gamma$-irradiation were studied.

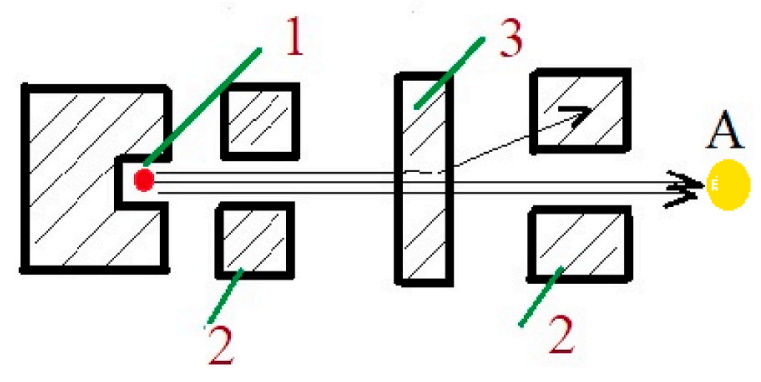

Fig. 2. Scheme of the experiment in the geometry of a "narrow" beam of gamma radiation: where 1 - radiation source; 2 - lead blocks; 3 - investigated material; A - detector.

\section{Materials and methods}

\subsection{Synthesis of materials}

Polymer composites based on PI and modified $\mathrm{WO}_{2}$ were synthesized. The use of PI as a binder can provide a high radiation resistance for the composites, which affects the durability of the materials. The use of $\mathrm{WO}_{2}$ creates strong protection against $\gamma$-radiation. The chemical formula of PI is shown in Fig. 1. The PI was a yellow pressed powder with a density of $1.4 \mathrm{~g} / \mathrm{cm}^{3}$ (JSC "Institute of Plastics", Moscow, Russia). The $\mathrm{WO}_{2}$ filler was a fine black-brown powder with a density of $12.1 \mathrm{~g} /$ $\mathrm{cm}^{3}$. One of the ways to create an even distribution of components is to modify the filler (Yastrebinsky et al., 2013; Matyukhin et al., 2013). Modification of the filler was carried out using an organosilicon modifier to create a hydrophobic surface. The use of a hydrophobic filler is necessary for good compatibility with a non-polar polymer PI matrix.

The mixing of the polymer particles and the modified filler was carried out in a jet-vortex mill. The homogeneous mixture was then placed in steel molds and hot pressing was carried out at a pressure of 80 $\mathrm{MPa}$ and a temperature of $360-380^{\circ} \mathrm{C}$. The finished product consisted of plates with dimensions of $25 \times 50 \mathrm{~mm}$ and thicknesses of $10-50 \mathrm{~mm}$ with a step of $10 \mathrm{~mm}$. A more detailed description of the method of making composites is presented in our previous work (Cherkashina et al., 2019).

Samples of the pure PI powder without filler and $\mathrm{PI} / \mathrm{WO}_{2}$ composites containing $60 \mathrm{wt} \% \mathrm{WO}_{2}$ were prepared. We previously found that the maximum $\mathrm{WO}_{2}$ content in the PI composite, at which high strength parameters are maintained, is $60 \mathrm{wt} \%$ (Cherkashina et al., 2019).

\subsection{Exposure to $\gamma$-sources}

Experimental studies of the effect of $\gamma$-radiation on the samples under study were carried out using the following radioisotope sources:

- Isotope source of gamma radiation ${ }^{137} \mathrm{Cs}(\mathrm{E}=0.662 \mathrm{MeV})$ with an activity of $1.88 \cdot 10^{8} \mathrm{~Bq}$, a gamma constant of radionuclide of 3.242 $\mathrm{R} \cdot \mathrm{cm}^{2} /(\mathrm{h} \cdot \mathrm{mCi})$ and a half-life of 30.17 years;

- Isotope source of gamma radiation ${ }^{60} \mathrm{Co}$ (average energy of gamma quanta of $1.252 \mathrm{MeV}$, considering two energy peaks of ${ }^{60} \mathrm{Co}$ with energies of 1.172 and $1.332 \mathrm{MeV}$ ) with an activity of $2.93 \cdot 10^{8} \mathrm{~Bq}$, a gamma constant of radionuclide of $12.853 \mathrm{R}^{\circ} \mathrm{cm}^{2} /(\mathrm{h} \cdot \mathrm{mCi})$ and a halflife of 5.27 years.

The used sources had dimensions of $0.5-1.0 \mathrm{~cm}$, which, in the first approximation, made it possible to consider them as "point" sources.

The measurements were carried out both under the conditions of a "narrow" geometry (without considering the scattered radiation) and under the conditions of the "wide" (considering the scattered radiation) beam of photon radiation. The scheme of the experiment in the conditions of a "narrow" beam is shown in Fig. 2 and the conditions of a 


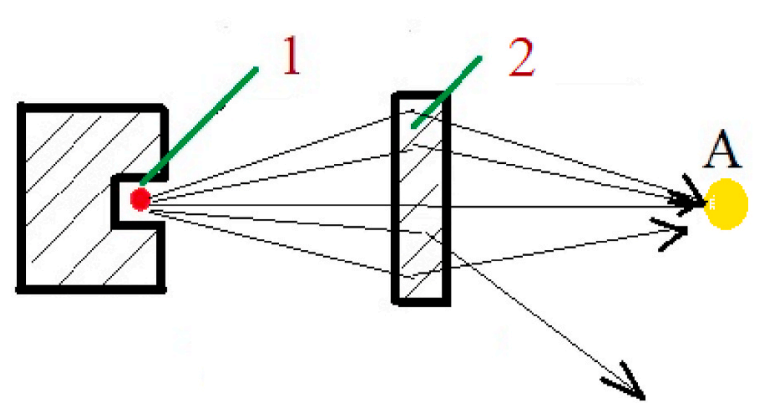

Fig. 3. Scheme of the experiment in the conditions of the geometry of the "wide" beam: where 1 - radiation source; 2 - investigated material; A - detector.

"wide" beam are given in Fig. 3.

An MKS-01 R radiometer-dosimeter with a BDKG-02 $\mathrm{R}$ detection unit based on tissue-equivalent scintillating plastic was used. This makes it possible to record the equivalent dose rate in a wide energy range (from 0.04 to $10.0 \mathrm{MeV}$ ) with limiting values and the basic error is $<20 \%$ with a confidence level of 0.95 .

To exclude the effect of scattered radiation in the experiment under the conditions of the "narrow" beam geometry, the sample under study was additionally surrounded by $10 \mathrm{~cm}$-thick shielding lead blocks on each side along the perimeter (Fig. 2).

Determination of the power of the effective equivalent and absorbed dose of gamma quanta was carried out under conditions when the thickness of the layer of the sample under study increases towards the source. The distance of the air gap between the source and the composite with a maximum thickness is $45 \mathrm{~cm}$, the maximum thickness of the test sample is $5 \mathrm{~cm}$ and the distance from the test material to the detector is $15 \mathrm{~cm}$.

\subsection{Research methods}

The linear attenuation coefficient of gamma radiation was calculated by Equation (1):

$I=I_{0} \cdot e^{-\mu \cdot d}$

where $I$ is intensity of $\gamma$-quanta absorption when using a protective screen; $I_{O}$ is intensity of $\gamma$-quanta absorption without a screen; $d$ is protective screen thickness.

The dose accumulation factor was calculated from the law of attenuation of gamma radiation in the conditions of the "wide" (considering the scattered radiation) beam of photon radiation:

$I=I_{0} \cdot B\left(\mu d, E, Z_{e f f}\right) e^{-\mu \cdot d}$

where $B(\mu d, E$, Zeff. $)$ is the dose accumulation factor is associated with the effective atomic number $\left(Z_{\text {eff. }}\right)$ composite, energy of gamma radiation (E) and product $\mu d$.

A TESCAN MIRA 3 LMU field emission electron microscope (TESCAN, Czech Republic) was used for scanning electron microscopy of the sample surface before and after gamma irradiation.

The Vickers microhardness of the surface was measured using a NEXUS 4504 hardness tester. A four-sided diamond Vickers pyramid with a square base and an apex angle between opposite faces of $136^{\circ}$ was used as an indenter. The load in all dimensions was the same (200 g).

The flexural strength was studied using a universal testing machine (Instron model 5882, 2007, Instron, USA). Flexural strength was calculated by Equation (3):

$\sigma_{\mathrm{f}, \mathrm{m}}=3 \mathrm{~F}_{\mathrm{m}} \times \mathrm{L} /\left(2 \mathrm{bh}^{2}\right)$

where $F_{m}$ is the maximum load, $\mathrm{N} ; L$ is the distance between the lower supports, $\mathrm{mm}$; $b$ is the sample width, $\mathrm{mm}$; $h$ is the average thickness of
Table 1

Values of attenuation of the absorbed dose rate of $\gamma$-radiation from point sources ${ }^{137} \mathrm{Cs}$ and ${ }^{60} \mathrm{Co}$ with a sample of pure PI (under the conditions of the geometry of a "narrow" beam).

\begin{tabular}{|c|c|c|c|c|c|}
\hline \multirow[t]{2}{*}{ No } & \multirow{2}{*}{$\begin{array}{l}\text { Sample } \\
\text { thickness, } \\
\mathrm{cm}\end{array}$} & \multicolumn{2}{|c|}{${ }^{137} \mathrm{Cs}(\mathrm{E}=0.662 \mathrm{MeV})$} & \multicolumn{2}{|c|}{${ }^{60} \mathrm{Co}(\mathrm{E}=1.252 \mathrm{MeV})$} \\
\hline & & $\begin{array}{l}\text { Absorbed } \\
\text { dose rate of } \\
\gamma \text {-quanta } \\
\text { behind the } \\
\text { sample, } \\
\mu \mathrm{Gy} / \mathrm{h}\end{array}$ & $\begin{array}{l}\text { Attenuation } \\
\text { factor }\end{array}$ & $\begin{array}{l}\text { Absorbed } \\
\text { dose rate of } \\
\gamma \text {-quanta } \\
\text { behind the } \\
\text { sample, } \\
\mu G y / h\end{array}$ & $\begin{array}{l}\text { Attenuation } \\
\text { factor }\end{array}$ \\
\hline 1 & 1 & 47.5 & 1.124 & 302 & 1.088 \\
\hline 2 & 2 & 42.2 & 1.263 & 277 & 1.185 \\
\hline 3 & 3 & 37.6 & 1.420 & 255 & 1.290 \\
\hline 4 & 4 & 33.4 & 1.596 & 234 & 1.405 \\
\hline 5 & 5 & 29.7 & 1.794 & 215 & 1.529 \\
\hline
\end{tabular}

the sample, mm.

The dielectric constant $\epsilon$ was calculated based on the experimental value of the electrical capacity according to Equation (4):

$\varepsilon=\frac{C \cdot d}{S \cdot \varepsilon_{0}}$

where $C$ is the electrical capacity of the sample, $\mathrm{F}$; $d$ is sample thickness, $\mathrm{m} ; \epsilon_{0}$ is the vacuum dielectric constant $8.85 \times 10^{-12} \mathrm{~F} \mathrm{~m}^{-1}$; $\mathrm{S}$ is electrode area (capacitor plate), $\mathrm{m}^{2}$

The tangent of the dielectric loss angle was calculated by Equation (5):

$\operatorname{tg} \cdot \delta=6.28 \times \mathrm{f} \times \mathrm{C} \times \mathrm{R} \times 10^{-12}$

where $\mathrm{f}$ is frequency, $10^{3} \mathrm{~Hz} ; C$ is the electrical capacity of the sample, $\mathrm{pF} ; R$ is the measured equivalent surface resistance, $\mathrm{Ohm}$.

Surface resistance (R) was measured using an RLC measuring bridge and metal electrodes located at a distance of $1 \mathrm{~cm}$ apart.

\section{Results and discussion}

\subsection{Attenuation of absorbed dose rate of $\gamma$-radiation under "narrow" geometry conditions}

In the experiment, the differential and integral energy distributions of the flux densities of $\gamma$-quanta of the incident radiation from the source without the test samples and behind the test samples were measured. On their basis, the corresponding distributions of the effective equivalent dose rate $(\mu \mathrm{Sv} / \mathrm{h})$ and the absorbed dose rate $(\mu \mathrm{Gy} / \mathrm{h})$ for $\gamma$-quanta were obtained.

It is known that for a point source of gamma radiation, the exposure dose rate is directly proportional to the activity (A) of the radionuclide and is inversely proportional to the square of the distance (r) from the source to the point of irradiation:

$\frac{X}{t}=k_{\gamma} \cdot \frac{A}{r^{2}}$

where $\mathrm{K}_{\gamma}$ is the gamma constant of the radionuclide.

Based on the differential and integral energy distributions of the flux densities of the gamma quanta of the incident radiation from the source without the samples under study, the corresponding values of the effective equivalent dose rate at a distance of $65 \mathrm{~cm}$ from the source were obtained: $53.4 \mu \mathrm{Sv} / \mathrm{h}$ for the ${ }^{137} \mathrm{Cs}$ source and $329 \mu \mathrm{Sv} / \mathrm{h}$ for the ${ }^{60}$ Co source.

Since the equivalent dose (dose rate) is related to the absorbed quality factor and for gamma radiation the value of the quality factor is 1 , the absorbed dose rates at a distance of $65 \mathrm{~cm}$ from the sources used in the work are $53.4 \mu \mathrm{Gy} / \mathrm{h}$ for the ${ }^{137} \mathrm{Cs}$ source and $329 \mu \mathrm{Gy} / \mathrm{h}$ for the ${ }^{60} \mathrm{Co}$ source. 
Table 2

Values of attenuation of the absorbed dose rate of $\gamma$-radiation from point sources $^{137} \mathrm{Cs}$ and ${ }^{60} \mathrm{Co}$ with a sample made of $\mathrm{PI} / \mathrm{WO}_{2}$ composite $(60 \mathrm{wt} \%$ ) (under the conditions of the geometry of a "narrow" beam).

\begin{tabular}{|c|c|c|c|c|c|}
\hline \multirow[t]{2}{*}{ No } & \multirow{2}{*}{$\begin{array}{l}\text { Sample } \\
\text { thickness, } \\
\mathrm{cm}\end{array}$} & \multicolumn{2}{|c|}{${ }^{137} \mathrm{Cs}(\mathrm{E}=0.662 \mathrm{MeV})$} & \multicolumn{2}{|c|}{${ }^{60} \mathrm{Co}(\mathrm{E}=1.252 \mathrm{MeV})$} \\
\hline & & $\begin{array}{l}\text { Absorbed } \\
\text { dose rate of } \\
\gamma \text {-quanta } \\
\text { behind the } \\
\text { sample, } \\
\mu \mathrm{Gy} / \mathrm{h}\end{array}$ & $\begin{array}{l}\text { Attenuation } \\
\text { factor }\end{array}$ & $\begin{array}{l}\text { Absorbed } \\
\text { dose rate of } \\
\gamma \text {-quanta } \\
\text { behind the } \\
\text { sample, } \\
\mu \mathrm{Gy} / \mathrm{h}\end{array}$ & $\begin{array}{l}\text { Attenuation } \\
\text { factor }\end{array}$ \\
\hline 1 & 1 & 36.77 & 1.452 & 269 & 1.222 \\
\hline 2 & 2 & 25.33 & 2.108 & 220 & 1.495 \\
\hline 3 & 3 & 17.44 & 3.062 & 180 & 1.827 \\
\hline 4 & 4 & 12.01 & 4.446 & 147 & 2.234 \\
\hline 5 & 5 & 8.27 & 6.456 & 120 & 2.732 \\
\hline
\end{tabular}

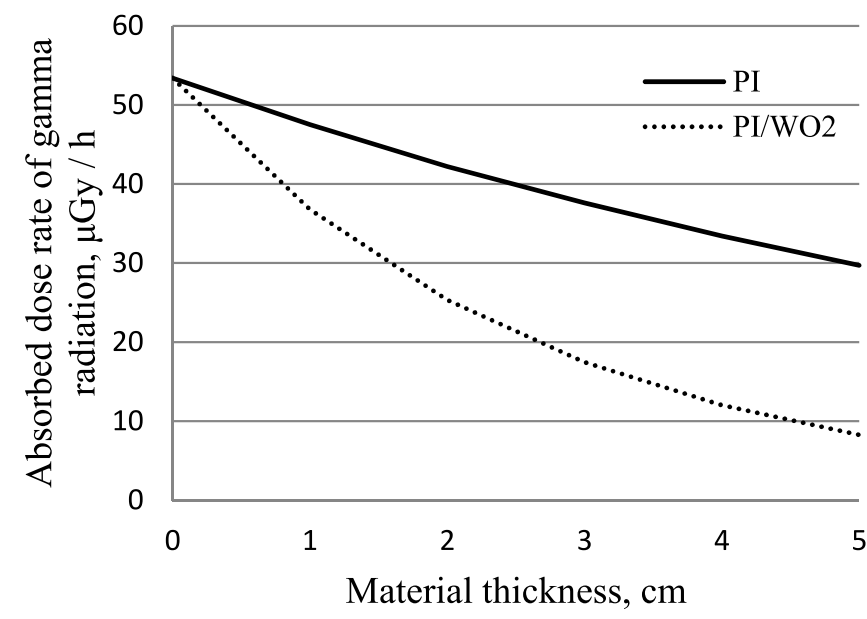

b

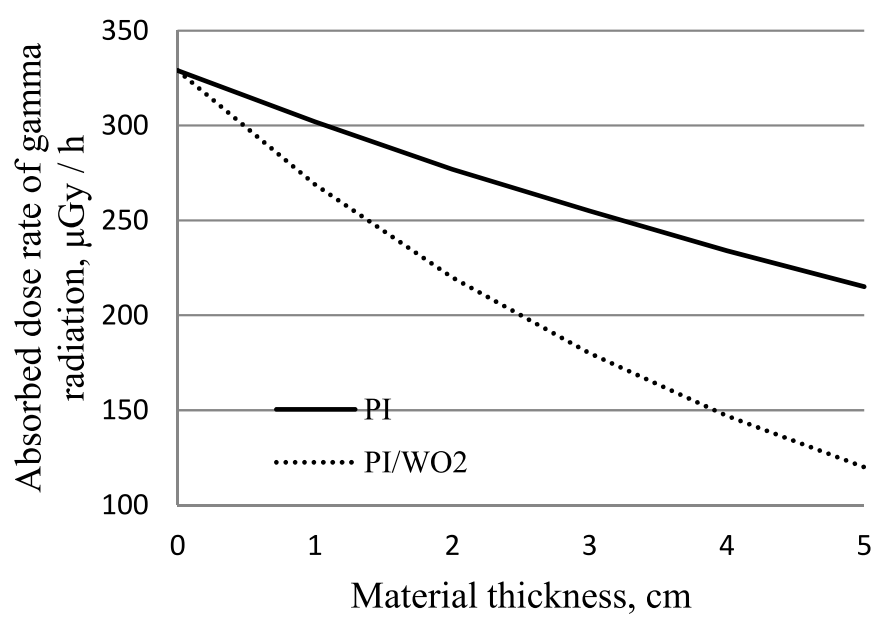

Fig. 4. Distribution of the absorbed dose rate of $\gamma$-radiation from the ${ }^{137} \mathrm{Cs}$ (a) and ${ }^{60} \mathrm{Co}$ (b) source in the materials under study in the conditions of the "narrow" beam geometry.

The experimentally obtained values of attenuation of the absorbed dose rate of gamma radiation from point sources ${ }^{137} \mathrm{Cs}$ and ${ }^{60} \mathrm{Co}$ by the materials under study are presented in Tables 1 and 2. For clarity, Fig. 4 shows the distribution of the absorbed dose rate of gamma radiation from the ${ }^{137} \mathrm{Cs}$ and ${ }^{60} \mathrm{Co}$ sources in the materials under the conditions of the "narrow" beam geometry.

Analysis of the data presented in Table 1 shows that the attenuation
Table 3

Linear and mass attenuation coefficients of $\gamma$-radiation in the materials under study.

\begin{tabular}{|c|c|c|c|c|c|c|}
\hline \multirow[t]{2}{*}{ No } & \multirow[t]{2}{*}{ Material } & \multirow{2}{*}{$\begin{array}{l}\text { Density, } \\
\left(\mathrm{g} / \mathrm{cm}^{3}\right)\end{array}$} & \multicolumn{2}{|c|}{$\mathrm{E}=0.662 \mathrm{MeV}$} & \multicolumn{2}{|c|}{$\mathrm{E}=1.252 \mathrm{MeV}$} \\
\hline & & & $\mathrm{cm}^{-1}$ & $\begin{array}{l}/ \rho, \\
\mathrm{cm}^{2} / \mathrm{g}\end{array}$ & $\mathrm{cm}^{-1}$ & $\begin{array}{l}/ \rho, \\
\mathrm{cm}^{2} / \\
\mathrm{g}\end{array}$ \\
\hline 1 & PI & 1.43 & 0.117 & 0.081 & 0.085 & 0.059 \\
\hline 2 & $\mathrm{PI} / \mathrm{WO}_{2}(60 \mathrm{wt} \%)$ & 3.03 & 0.373 & 0.123 & 0.201 & 0.066 \\
\hline 3 & $\begin{array}{l}\text { Ordinary concrete ( } \\
\text { Sharifi et al., 2013) }\end{array}$ & 2.3 & 0.1813 & 0.0788 & - & - \\
\hline 4 & $\begin{array}{l}\text { Barite concrete ( } \\
\text { Sharifi et al., 2013) }\end{array}$ & 3.35 & 0.2618 & 0,0781 & - & - \\
\hline 5 & $\begin{array}{l}\text { Barium-Bismuth- } \\
\text { Borosilicate Glasses } \\
\text { (50-20-30) (mol\%) ( } \\
\text { Bagheri et al., 2017b) }\end{array}$ & 4.21 & 0.3544 & 0.0842 & - & - \\
\hline 6 & $\begin{array}{l}\text { Silicate glasses } \\
\text { containing } \mathrm{Bi}_{2} \mathrm{O}_{3} 60 \\
\text { wt } \% \text { (Bagheri et al., } \\
2018 \mathrm{~b} \text { ) }\end{array}$ & 5.487 & 0.524 & 0.0955 & & \\
\hline
\end{tabular}

factor increases with increasing thickness of the polyimide. With an increase in the sample thickness PI from $1 \mathrm{~cm}$ to $5 \mathrm{~cm}$, the attenuation factor value increases by $59.6 \%$. A similar situation is observed with increasing thickness of the $\mathrm{PI} / \mathrm{WO}_{2}$ composite (Table 2). With an increase in $\mathrm{PI} / \mathrm{WO}_{2}$ composite thickness from $1 \mathrm{~cm}$ to $5 \mathrm{~cm}$, the attenuation factor value increases by 4.44 times. Based on the law of attenuation of $\gamma$-radiation in matter (Equation (1)), the attenuation factor value depends not only on the composition of the substance itself, the energy of $\gamma$-quanta, but also on the thickness of the material itself (x), which is observed in Tables 1 and 2 With the same thickness of the studied samples, the attenuation factor is the highest for the $\mathrm{PI} / \mathrm{WO}_{2}$ composite and the lowest for the pure PI sample. This can be explained by the content in the composite of a large number of $\mathrm{W}$ particles, on which a greater scattering of $\gamma$-quanta occurs.

Based on the data presented in Tables 1 and 2 and the law of attenuation of X-rays and gamma rays when they pass through a layer of matter with thickness d (Equation (1)), the linear and mass attenuation coefficients of $\gamma$-radiation in the materials under study were calculated (Table 3). Table 3 also shows the linear attenuation coefficient of some famous shielding materials such as, ordinary and barite concretes, and some silicate based shielding glass materials in order to compare with developed polymer composite.

From the data in Table 3 , it is noticeable that the introduction of the proposed $\mathrm{WO}_{2}$ filler at $60 \mathrm{wt} \%$ more than triples the linear attenuation coefficient of $\gamma$-radiation at $\mathrm{E}=0.662 \mathrm{MeV}$ and 2.36 times as large at $\mathrm{E}$ $=1.252 \mathrm{MeV}$. For all of the concrete samples presented in Table 3, the linear and mass attenuation coefficients of $\gamma$-radiation are less than PI/ $\mathrm{WO}_{2}$ composite.

The linear and mass attenuation coefficients of $\gamma$-radiation of the presented glasses (Table 3 ) are higher than $\mathrm{PI} / \mathrm{WO}_{2}$ composite. This is due to the significantly higher density of the glasses compared to the density of the $\mathrm{PI} / \mathrm{WO}_{2}$ composite.

\subsection{Dose accumulation factors}

The linear coefficient of attenuation of the flux of $\gamma$-quanta and the multiplicity of attenuation are not exhaustive characteristics of the protective properties of materials. The reason for this incompleteness is the processes leading to the appearance of scattered and secondary radiation. In some cases, such a contribution to the dose behind protection may exceed the dose from attenuated primary radiation by one to two orders of magnitude (Benetskii and Plotnikova, 2012). This effect is considered by introducing a factor B into the exponential law of attenuation of the primary beam, which depends on the effective atomic number $\mathrm{Z}_{\text {eff. }}$ composite, energy of gamma radiation and product $\mu \mathrm{d}$. 
a

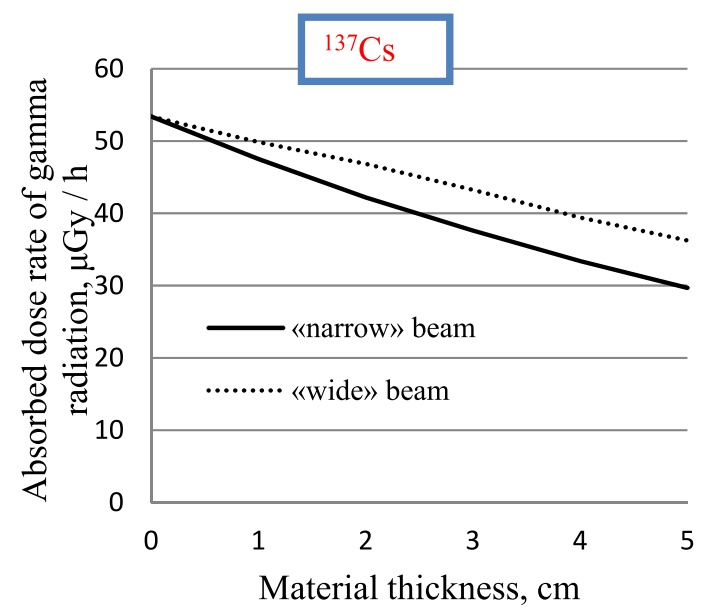

c

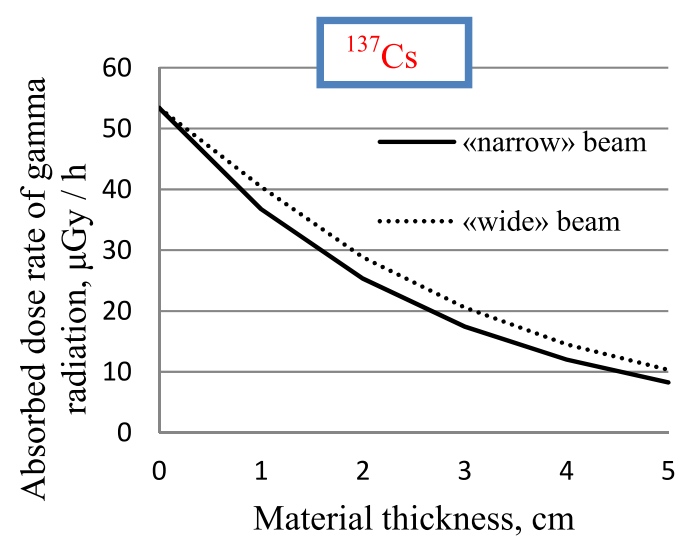

b

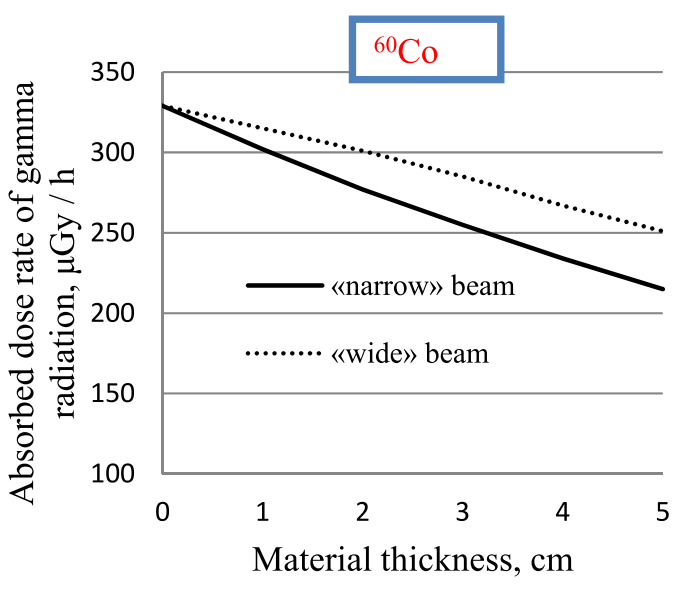

d

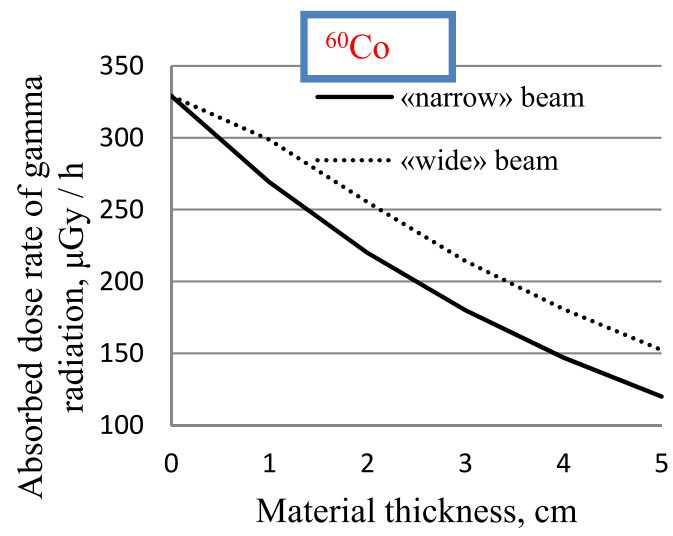

Fig. 5. Distribution of the absorbed dose rate of gamma radiation in the samples: a, b - PI; c, d - composite PI/WO 2 (60 wt $\%)$.

Table 4

Values of dose accumulation factors in the test materials.

\begin{tabular}{|c|c|c|c|c|c|}
\hline \multirow[t]{3}{*}{ No } & \multirow{3}{*}{$\begin{array}{l}\text { Material } \\
\text { thickness, cm }\end{array}$} & \multicolumn{4}{|l|}{ Material } \\
\hline & & \multicolumn{2}{|l|}{ PI } & \multicolumn{2}{|c|}{$\mathrm{PI} / \mathrm{WO}_{2}(60 \mathrm{wt} \%)$} \\
\hline & & $\begin{array}{l}{ }^{137} \mathrm{Cs}(\mathrm{E}= \\
0.662 \mathrm{MeV})\end{array}$ & $\begin{array}{l}{ }^{60} \mathrm{Co}(\mathrm{E}= \\
1.252 \mathrm{MeV})\end{array}$ & $\begin{array}{l}{ }^{137} \mathrm{Cs}(\mathrm{E}= \\
0.662 \mathrm{MeV})\end{array}$ & $\begin{array}{l}{ }^{60} \mathrm{Co}(\mathrm{E}= \\
1.252 \mathrm{MeV})\end{array}$ \\
\hline 1 & 1 & 1.05 & 1.03 & 1.11 & 1.10 \\
\hline 2 & 2 & 1.11 & 1.08 & 1.16 & 1.14 \\
\hline 3 & 3 & 1.15 & 1.11 & 1.19 & 1.18 \\
\hline 4 & 4 & 1.18 & 1.14 & 1.23 & 1.21 \\
\hline 5 & 5 & 1.22 & 1.16 & 1.27 & 1.25 \\
\hline
\end{tabular}

Fig. 5 shows the attenuation functions of the absorbed dose of $\gamma$-radiation by the materials under conditions that consider the scattered and unscattered radiation of primary and secondary $\gamma$-quanta (curve 1 , «wide » beam), as well as only unscattered primary radiation (curve 2, «narrow » beam). The calculated numerical values of the dose accumulation factor are presented in Table 4.

As can be seen from the data obtained (Table 4), the accumulation factors monotonically increase with the thickness of the samples under study, which is explained by an increase in the fraction of scattered radiation in the material. With the same thickness of the studied samples, the value of the dose accumulation factor is the highest for the PI/ $\mathrm{WO}_{2}$ composite and the lowest for the pure PI sample. This can be explained by the content in the composite of a large number of $\mathrm{W}$ particles, on which a greater scattering of gamma quanta occurs. It can also be noted that, other things being equal, the accumulation factor decreases with increasing radiation energy.

The obtained values of the dose accumulation factor in the materials under study are not large and fluctuate within the range of 1.03-1.27 (Table 4). Such low values of the accumulation factor are associated with the small size of the irradiation field of the material $5 \times 2.5 \mathrm{~cm}$. It is known that the dose accumulation factor is associated not only with the effective atomic number $Z_{\text {eff. }}$ composite, energy of gamma radiation and product $\mu \mathrm{d}$, but also depends on the size of the irradiation field. An increase in the size of the irradiation field leads to an increase in the dose accumulation factor (Chetty and Rosu-Bubulac, 2019).

\subsection{Radiation resistance of $\mathrm{PI} / \mathrm{WO}_{2}$ composite}

PI and materials based on it have a high radiation resistance to gamma radiation. It was revealed that irradiation of PI by $\mathrm{a}^{60} \mathrm{Co}$ source up to a dose of $230.4 \mathrm{kGy}$ (the maximum accumulated dose in the work) does not cause significant changes in the structure and properties of PI, which were characterized by Fourier transform infrared spectroscopy, energy dispersive spectroscopy, X-ray phase analysis and scanning electron microscopy (Mathakari et al., 2014). PI demonstrated remarkable stability for the properties under study.

It was shown that PI practically did not change either in its physical or electrical properties at doses of gamma radiation $\left({ }^{60} \mathrm{Co}\right)$ up to $10 \mathrm{MGy}$ (Markley et al., 1969). The tensile strength remained practically 
Table 5

Properties of the materials under study before and after $\gamma$-irradiation at $\mathrm{E}=1.25$ $\mathrm{MeV}$ and an absorbed dose of $10 \mathrm{MGy}$.

\begin{tabular}{|c|c|c|c|c|c|}
\hline \multirow[t]{3}{*}{ No } & \multirow{3}{*}{$\begin{array}{l}\text { Description of } \\
\text { characteristics }\end{array}$} & \multicolumn{4}{|l|}{ Material } \\
\hline & & \multicolumn{2}{|l|}{ PI } & \multicolumn{2}{|c|}{$\mathrm{PI} / \mathrm{WO}_{2}(60 \mathrm{wt} \%)$} \\
\hline & & $\begin{array}{l}\text { Before } \\
\text { irradiation }\end{array}$ & $\begin{array}{l}\text { After } \\
\text { irradiation }\end{array}$ & $\begin{array}{l}\text { Before } \\
\text { irradiation }\end{array}$ & $\begin{array}{l}\text { After } \\
\text { irradiation }\end{array}$ \\
\hline 1 & $\begin{array}{l}\text { Vickers } \\
\text { microhardness at } \\
200 \mathrm{~g} \text { load (HV) }\end{array}$ & $\begin{array}{l}37.79 \pm \\
2.50\end{array}$ & $\begin{array}{l}36.5 \pm \\
2.15\end{array}$ & $\begin{array}{l}57.2 \pm \\
5.65\end{array}$ & $\begin{array}{l}56.5 \pm \\
4.78\end{array}$ \\
\hline 2 & $\begin{array}{l}\text { Flexural } \\
\text { strength, MPa }\end{array}$ & $\begin{array}{l}93.71 \pm \\
4.73\end{array}$ & $\begin{array}{l}91.75 \pm \\
4.59\end{array}$ & $\begin{array}{l}88.52 \pm \\
4.47\end{array}$ & $\begin{array}{l}89.8 \pm \\
5.25\end{array}$ \\
\hline 3 & $\begin{array}{l}\text { Dielectric } \\
\text { constant }(\varepsilon)\end{array}$ & 3.05 & 3.02 & 7.6 & 7.6 \\
\hline 4 & $\begin{array}{l}\text { Dielectric loss } \\
\text { tangent }(\operatorname{tg} \delta)\end{array}$ & 0.02 & 0.02 & 0.052 & 0.051 \\
\hline
\end{tabular}

constant up to a dose of $10 \mathrm{MGy}$ but decreased to about half of its original value at an absorbed dose of $60 \mathrm{MGy}$. The specific electrical resistance remained at the level of $10^{19} \mathrm{Ohm} \cdot \mathrm{cm}$ or higher and decreased only to $3 \cdot 10^{18} \mathrm{Ohm} \cdot \mathrm{cm}$ at a total dose of $100 \mathrm{MGy}$. The same dose left the dielectric constant practically unchanged and reduced the breakdown voltage to $\sim 75 \%$ of the original value.

To assess the radiation resistance of the developed $\mathrm{PI} / \mathrm{WO}_{2}$ composite under $\gamma$-irradiation, it was irradiated in the barrier geometry of the shielding on $\mathrm{a}^{60} \mathrm{Co}$ research $\gamma$-installation with a dose rate from a source of $0.021 \mathrm{MGy} / \mathrm{h}$ at an energy of $1.25 \mathrm{MeV}$. The maximum absorbed dose in the experiment was $10 \mathrm{MGy}$. The set of such a dose was carried out continuously for 20 days. It was found that at a dose of 10 MGy, the studied samples PI and PI/ $\mathrm{WO}_{2}(60 \mathrm{wt} \%)$ completely retain their physical and mechanical characteristics, as assessed by the Vickers microhardness and bending strength, as well as the electrical properties $\varepsilon, \operatorname{tg} \delta$ (Table 5). A small change in the studied parameters is within the error of the experiment. Scanning electron microscopy (Fig. 6) also did not record any changes in the surface structure of the composites. No cracks or delamination were detected after $\gamma$-irradiation of PI and a composite with $\mathrm{WO}_{2}$. Thus, a high radiation resistance of the developed $\mathrm{PI} / \mathrm{WO}_{2}$ composites ( $60 \mathrm{wt} \%$ ) was established up to a dose of $10 \mathrm{MGy}$. Experiments were not carried out at a higher accumulated dose.

\section{Conclusions}

The high radiation shielding properties of $\mathrm{PI} / \mathrm{WO}_{2}$ composites $(60 \mathrm{wt}$ $\%$ filler) with respect to $\gamma$-radiation have been established. It is shown that the introduction of the proposed filler $\mathrm{WO}_{2}$ in the amount of $60 \mathrm{wt} \%$ more than triples the linear attenuation coefficient of $\gamma$-radiation at $\mathrm{E}=$ $0.662 \mathrm{MeV}$ and increases it 2.36 times at $\mathrm{E}=1.252 \mathrm{MeV}$.

It was found that under the conditions of the "wide" beam geometry, the value of the absorbed dose rate behind the test sample is higher than under the conditions of the "narrow" beam geometry. It was found that a
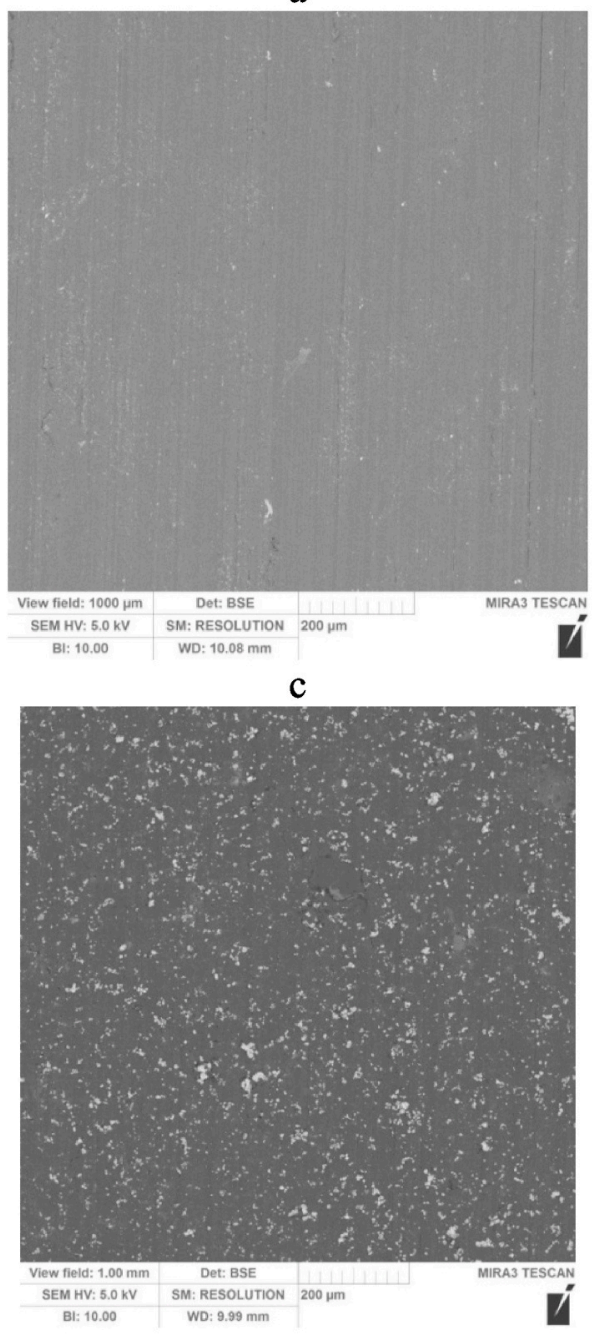

b

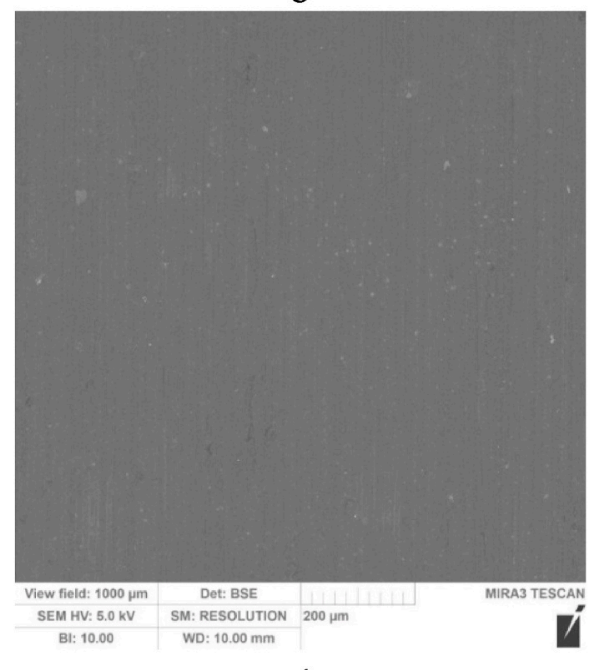

d

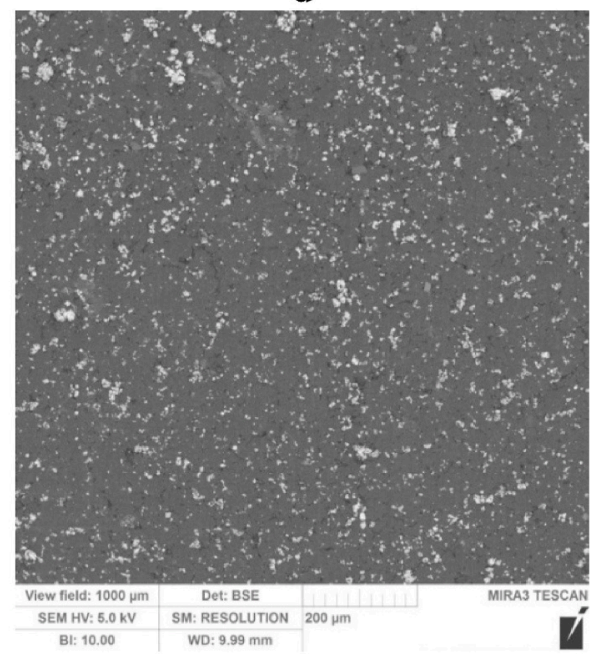

Fig. 6. SEM-images of PI sample (a, b) and PI/WO $(c, d): a, c$ - before $\gamma$-irradiation, b, d - after $\gamma$-irradiation (10 MGy). 
the accumulation factors monotonically increase with the thickness of the samples under study, which is explained by an increase in the fraction of scattered radiation in the material. With the same thickness of the studied samples, the value of the dose accumulation factor is the highest for the $\mathrm{PI} / \mathrm{WO}_{2}$ composite and the lowest for the pure PI sample. The obtained values of the dose accumulation factor in the studied materials are not large and fluctuate within the range of 1.03-1.27.

The high radiation resistance of the developed $\mathrm{PI} / \mathrm{WO}_{2}$ composites (60 $\mathrm{wt} \%$ ) was established up to a dose of $10 \mathrm{MGy}$. At a dose of $10 \mathrm{MGy}$, the studied samples PI and PI/ $\mathrm{WO}_{2}(60 \mathrm{wt} \%$ ) fully retain their physical and mechanical characteristics, as assessed by the Vickers microhardness and bending strength, as well as the electrical properties $\varepsilon$, tgס.

\section{Funding}

The work was supported by a project of the Russian Science Foundation (№19-19-00316). The work is realized using equipment of High Technology Center at BSTU named after V.G. Shukhov.

\section{Declaration of competing interest}

The authors declare that they have no known competing financial interests or personal relationships that could have appeared to influence the work reported in this paper.

\section{References}

Abouhaswa, A.S., Kavaz, E., 2020. A novel $\mathrm{B}_{2} \mathrm{O}_{3}-\mathrm{Na}_{2} \mathrm{O}-\mathrm{BaO}-\mathrm{HgO}$ glass system: synthesis, physical, optical and nuclear shielding features. Ceram. Int. 46, 16166-16177. https://doi.org/10.1016/j.ceramint.2020.03.172.

Abramyan, S.G., Burlachenko, O.V., Oganesyan, O.V., 2019. The use of composite materials in the reconstruction of floors of industrial buildings. Construction Materials and Products 2 (3), 58-64.

AbuAlRoos, N.J., Amin, N.A.B., Zainon, R., 2019. Conventional and new lead-free radiation shielding materials for radiation protection in nuclear medicine: a review. Radiat. Phys. Chem. 165, 108439. https://doi.org/10.1016/j. radphyschem.2019.108439.

Akman, F., Ogul, H., Kaçal, M.R., Polat, H., Dilsiz, K., Agar, O., 2021. Gamma attenuation characteristics of CdTe-Doped polyester composites. Prog. Nucl. Energy 131, 103608. https://doi.org/10.1016/j.pnucene.2020.103608.

Almuqrin, A.H., Sayyed, M.I., 2021. Radiation shielding characterizations and investigation of $\mathrm{TeO}_{2}-\mathrm{WO}_{3}-\mathrm{Bi}_{2} \mathrm{O}_{3}$ and $\mathrm{TeO}_{2}-\mathrm{WO}_{3}-\mathrm{PbO}$ glasses. Appl. Phys. 127, 190. https://doi.org/10.1007/s00339-021-04344-9.

Apel, P.Y., Blonskaya, I.V., Oganessian, V.R., Orelovitch, O.L., Trautmann, C., 2001. Morphology of latent and etched heavy ion tracks in radiation resistant polymers polyimide and poly(ethylene naphthalate). Nucl. Instrum. Methods B. 185, 216-221. https://doi.org/10.1016/S0168-583X(01)00967-3.

Arbuzova, A.A., Votyakov, M.A., 2018. Estimation of the influence of the state of the reinforcing polymer in the structure of polymeric fiber material using mathematical prediction methods. Chem. Bull. 1, 12-17.

Aygün, B., 2020. High alloyed new stainless steel shielding material for gamma and fast neutron radiation. Nucl. Eng. Technol. 52, 647-653. https://doi.org/10.1016/j. net.2019.08.017.

Bagheri, R., Adeli, R., 2020. Gamma-ray shielding properties of phosphate glasses containing $\mathrm{Bi}_{2} \mathrm{O}_{3}, \mathrm{PbO}$, and $\mathrm{BaO}$ in different rates. Radiat. Phys. Chem. 174, 108918. https://doi.org/10.1016/j.radphyschem.2020.108918.

Bagheri, R., Shirmardi, S.P., 2021. Gamma-ray shielding studies on borate glasses containing $\mathrm{BaO}, \mathrm{Bi}_{2} \mathrm{O}_{3}$, and $\mathrm{PbO}$ in different concentrations. Radiat. Phys. Chem 184, 109434. https://doi.org/10.1016/j.radphyschem.2021.109434.

Bagheri, R., Moghaddam, A.K., Yousefi, A., 2017a. Gamma-ray shielding study of light to heavyweight concretes using MCNP-4C code. Nucl. Sci. Tech. 28, 15. https://doi. org/10.1007/s41365-016-0167-6.

Bagheri, R., Moghaddam, A.K., Yousefnia, H., 2017b. Gamma ray shielding study of Barium-Bismuth-Borosilicate glasses as transparent shielding materials using MCNP4C code, XCOM program, and available experimental data. Nucl. Eng. Technol. 49, 216-223. https://doi.org/10.1016/j.net.2016.08.013.

Bagheri, K., Razavi, S.M., Ahmadi, S.J., Kosari, M., Abolghasemi, H., 2018a. Thermal resistance, tensile properties, and gamma radiation shielding performance of unsaturated polyester/nanoclay/PbO composites. Radiat. Phys. Chem. 146 (2018), 5-10. https://doi.org/10.1016/j.radphyschem.2017.12.024. ISSN 0969-806X.

Bagheri, R., Moghaddam, A.K., Shirmardi, S.P., Azadbakht, B., Salehi, M., 2018b. Determination of gamma-ray shielding properties for silicate glasses containing $\mathrm{Bi}_{2} \mathrm{O}_{3}, \mathrm{PbO}$, and BaO. J. Non-Cryst. Solids 479 (2018), 62-71.

Bagheri, K., Razavi, S.M., Ahmadi, S.J., Kosari, M., Abolghasemi, H., Akman, F., Kaçal, M.R., Almousa, N., Sayyed, M.I., Polat, H., 2020. Gamma-ray attenuation parameters for polymer composites reinforced with $\mathrm{BaTiO}_{3}$ and $\mathrm{CaWO}_{4}$ compounds. Prog. Nucl. Energy 121, 103257. https://doi.org/10.1016/j.pnucene.2020.103257.
Bakar, Nurul Fathihah Abu, Othman, Siti Amira, Azman, Nor Farah Amirah Nor, Jasrin, Nurin Saqinah, 2019. Effect of ionizing radiation towards human health: a review. IOP Conf. Ser. Earth Environ. Sci. 268, 012005 https://doi.org/10.1088/ 1755-1315/268/1/012005.

Benetskii, B.A., Plotnikova, M.V., 2012. Gamma-radiation accumulation factors for composite materials and radiation shields. Bull. Lebedev Phys. Inst. 39, 113-117. https://doi.org/10.3103/S1068335612040045.

Cao, D., Yang, G., Bourham, M., Moneghan, D., 2020. Gamma radiation shielding properties of poly (methyl methacrylate) $/ \mathrm{Bi}_{2} \mathrm{O}_{3}$ composites. Nucl. Eng. Technol. 52, 2613-2619. https://doi.org/10.1016/j.net.2020.04.026.

Cherkashina, N.I., Pavlenko, A.V., 2018. Modification of optical characteristics of a polymer composite material under irradiation. Tech. Phys. 63, 571-575. https://doi. org/10.1134/S1063784218040072.

Cherkashina, N.I., Pavlenko, V.I., Noskov, A.V., 2019. Synthesis and property evaluations of highly filled polyimide composites under thermal cycling conditions from $-190^{\circ} \mathrm{C}$ to $+200{ }^{\circ}$ C. Cryogenics 104,102995 . https://doi.org/10.1016/j. cryogenics.2019.102995.

Chetty, I.J., Rosu-Bubulac, M., 2019. Deformable registration for dose accumulation. Semin. Radiat. Oncol. 29 (3), 198-208. https://doi.org/10.1016/j. semradonc.2019.02.002.

Devasahayam, S., Hill, D.J.T., Connell, J.W., 2001. A comparative study of the radiation resistance of four optically transparent polyimides. Radiat. Phys. Chem. 62, 18-194. https://doi.org/10.1016/S0969-806X(01)00437-6.

Dionisio, A.P., Gomes, R.T., Oetterer, M., 2009. Ionizing radiation effects on food vitamins: a review. Braz. Arch. Biol. Technol. 52, 1267-1278. https://doi.org/ 10.1590/S1516-89132009000500026.

Dong, M., Xue, X., Yang, H., Li, Z., 2017. Highly cost-effective shielding composite made from vanadium slag and boron-rich slag and its properties, Radiat. Phys. Chem. 141, 239-244. https://doi.org/10.1016/j.radphyschem.2017.07.023.

Ghobashy, M.M., Abdeen, Z.I., 2016. Radiation crosslinking of polyurethanes: characterization by FTIR, TGA, SEM, XRD, and Raman spectroscopy. J. Polym. 2016 https://doi.org/10.1155/2016/9802514. Article ID 9802514.

Harrison, C., Burgett, E., Hertel, N., Grulke, E., 2008. Polyethylene/boron composites for radiation shielding applications. In: AIP Conf. Proc, vol. 969, p. 484. https://doi.org/ 10.1063/1.2845006, 2008.

Intom, S., Kalkornsurapranee, E., Johns, J., Kaewjaeng, S., Kothan, S., Hongtong, W., Chaiphaksa, W., Kaewkhao, J., 2020. Mechanical and radiation shielding properties of flexible material based on natural rubber $/ \mathrm{Bi}_{2} \mathrm{O}_{3}$ composites. Radiat. Phys. Chem. 172, 108772. https://doi.org/10.1016/j.radphyschem.2020.108772.

Klinshpont, É.R., Milinchuk, V.K., Tupikov, V.I., 1994. Radiation resistance of polymer materials. At. Energy. 76, 384-389. https://doi.org/10.1007/BF02407450.

Körpınar, B., Öztürk, B.C., Çam, N.F., Akat, H., 2020. Investigations on thermal and radiation shielding properties of the poly(hydroxyethyl methacrylate-co-styrene)/ tungsten(VI) oxide composites. Prog. Nucl. Energy 126, 103424. https://doi.org/ 10.1016/j.pnucene.2020.103424.

Markley, F., Forster, G.A., Booth, R., Argonne National Lab., Argonne, III., 1969. Radiation damage studies of zero gradient synchrotron magnet insulation and related materials. In: Paper Presented at the 1969 Particle Accelerator Conference on Accelerator Engineering and Technology, Shoreham Hotel, Washington, D. C., March 5-7, 1969, IEEE Transactions on Nuclear Science, NS- 16, (3) June, pp. 606-610. BRC 41627.

Maruzhenko, O., Mamunya, Y., Boiteux, G., Pusz, S., Szeluga, U., Pruvost, S., 2019. Improving the thermal and electrical properties of polymer composites by ordered distribution of carbon micro- and nanofillers. Int. J. Heat Mass Tran. 138, 75-84. https://doi.org/10.1016/j.ijheatmasstransfer.2019.04.043.

Mathakari, N.L., Bhoraskar, V.N., Dhole, S.D., 2014. A comparative study on the effects of Co-60 gamma radiation on polypropylene and polyimide. Radiat. Eff. Defect Solid 169, 779-790. https://doi.org/10.1080/10420150.2014.939176.

Matyukhin, P.V., Pavlenko, V.I., Yastrebinsky, R.N., Cherkashina, N.I., 2013. The highenergy radiation effect on the modified iron-containing composite material. Middle East J. Sci. Res. 17 (9), 1343-1349.

More, C.V., Alsayed, Z., Badawi, M.S., Thabet, A.A., Pawar, P.P., 2021. Polymeric composite materials for radiation shielding: a review. Environ. Chem. Lett. https:// doi.org/10.1007/s10311-021-01189-9.

Nambiar, S., Yeow, J.T.W., 2012. Polymer-composite materials for radiation protection. ACS Appl. Mater. Interfaces 4, 5717-5726. https://doi.org/10.1021/am300783d.

Navarro, R., Burillo, G., Adem, E., Marcos-Fernández, A., 2018. Effect of ionizing radiation on the chemical structure and the physical properties of polycaprolactones of different molecular weight. Polymers (Basel) 10 (4), 397. https://doi.org/ 10.3390 /polym10040397.

Pavlenko, V.I., Cherkashina, N.I., 2019. Effect of $\mathrm{SiO}_{2}$ crystal structure on the stability of polymer composites exposed to vacuum ultraviolet radiation. Acta Astronaut. 155, 1-9. https://doi.org/10.1016/j.actaastro.2018.11.017.

Pavlenko, V.I., Novikov, L.S., Bondarenko, G.G., Chernik, V.N., Gaidar, A.I., Cherkashina, N.I., Edamenko, O.D., 2013. Experimental and physicomathematical simulation $\mathrm{f}$ the effect of an incident flow of atomic oxygen on highly filled polymer composites. Inorg. Mater. Appl. Res. 4 (2), 169-173. https://doi.org/10.1134/ S2075113313020135.

Pavlenko, V.I., Zabolotny, V.T., Cherkashina, N.I., Edamenko, O.D., 2014. Effect of vacuum ultraviolet on the surface properties of high-filled polymer composites. Inorg. Mater. Appl. Res. 5 (3), 219-223. https://doi.org/10.1134/ S2075113314030137.

Pavlenko, V.I., Edamenko, O.D., Cherkashina, N.I., Kuprieva, O.V., Noskov, A.V., 2015. Study of the attenuation coefficients of photon and neutron beams passing through titanium hydride. J. Surf. Invest. 9, 546-549. https://doi.org/10.1134/ S1027451015030337. 
Pavlenko, V.I., Cherkashina, N.I., Zaitsev, S.V., 2019. Fabrication and characterization of nanocomposite films $\mathrm{Al}, \mathrm{Cu} / \mathrm{Al}$ and $\mathrm{Cr} / \mathrm{Al}$ formed on polyimide substrate. Acta Astronaut. 160, 489-498. https://doi.org/10.1016/j.actaastro.2019.02.025.

Plis, E.A., Engelhart, D.P., Cooper, R., Johnston, W.R., Ferguson, D., Hoffmann, R., 2019 Review of radiation-induced effects in polyimide. Appl. Sci. 9 (1999) https://doi. org/10.3390/app9101999.

Pomar, B., 2016. A review on radiation damage in concrete for nuclear facilities: from experiments to modeling. Model. Simulat. Eng. 2016 https://doi.org/10.1155/ 2016/4165746. Article ID 4165746.

Pradeep Kumar, K.A., Shanmugha Sundaram, G.A., Sharma, B.K., Venkatesh, S., Thiruvengadathan, R., 2020. Advances in gamma radiation detection systems for emergency radiation monitoring. Nucl. Eng. Technol. 52, 2151-2161. https://doi. org $/ 10.1016 /$ j.net.2020.03.014.

Rafiee, S.R., Eftekhari-Zadeh, E., Gholami, Y., 2017. A review on the status and future trends of radiation processing in Iran. J. Radiat. Res. Appl. Sc. 10 (4), 331-337. https://doi.org/10.1016/j.jrras.2017.08.004.

Ramani, R., Shariff, G., Thimmegowda, M.C., Sathyanarayana, P.M., Ashalatha, M.B., Balraj, A., Ranganathaiah, C., 2003. Influence of gamma irradiation on the formation of methanol induced micro-cracks in polycarbonate. J. Mater. Sci. 38, 1431-1438. https://doi.org/10.1023/A:1022951926769.

Sayyed, M.I., Akman, F., Kaçal, M.R., Kumar, A., 2019. Radiation protective qualities of some selected lead and bismuth salts in the wide gamma energy region. Nucl. Eng. Technol. 51, 860-866. https://doi.org/10.1016/j.net.2018.12.018.

Sayyed, M.I., Mahmoud, K.A., Tashlykov, O.L., Khandaker, M.U., Faruque, M.R.I., 2021a Enhancement of the shielding capability of soda-lime glasses with $\mathrm{Sb}_{2} \mathrm{O}_{3}$ dopant: a potential material for radiation safety in nuclear installations. Appl. Sci. 11, 326. https://doi.org/10.3390/app11010326.

Sayyed, M.I., Almuqrin, A.H., Kurtulus, R., Hila, A.M.V.J., Kaky, K., Kavas, T., 2021b. $X$ ray shielding characteristics of $\mathrm{P}_{2} \mathrm{O}_{5}-\mathrm{Nb}_{2} \mathrm{O}_{5}$ glass doped with $\mathrm{Bi}_{2} \mathrm{O}_{3}$ by using EPICS2017 and Phy X/PSD. Appl. Phys. A 127, 243. https://doi.org/10.1007/ s00339-021-04405-Z.

Sayyed, M.I., Al-Hadeethi, Y., AlShammari, M.M., Ahmed, M., Al-Heniti, S.H., Rammah, Y.S., 2021c. Physical, optical and gamma radiation shielding competence of newly borotellurite based glasses: $\mathrm{TeO}_{2}-\mathrm{B}_{2} \mathrm{O}_{3}-\mathrm{ZnO}-\mathrm{Li}_{2} \mathrm{O}_{3}-\mathrm{Bi}_{2} \mathrm{O}_{3}$. Ceram. Int. 47, 611-618. https://doi.org/10.1016/j.ceramint.2020.08.168.
Sayyed, M.I., Mahmoud, K.A., Lacomme, E., AlShammari, M.M., Dwaikat, N., Alajerami, Y.S.M., Alqahtani, M., El-bashir, B.O., Mhareb, M.H.A., 2021d. Development of a novel $\mathrm{MoO}_{3}$-doped borate glass network for gamma-ray shielding applications. Eur. Phys. J. Plus. 136, 108. https://doi.org/10.1140/epjp/s13360020-01011-5.

Scagliusi, S.R., Cardoso, E.C.L., Zaharescu, T., Lugão, A.B., 2016. Influence of gamma radiation on EPDM compounds properties for use in nuclear plants. AIP Conf. Proc. 1779, 080015 https://doi.org/10.1063/1.4965559.

Seguchi, T., Morita, Y., 1999. Radiation resistance of plastics and elastomer. Polymer Handbook 4, 583-586.

Sharifi, Sh, Bagheri, R., Shirmardi, S.P., 2013. Comparison of shielding properties for ordinary, barite, serpentine and steel-magnetite concretes using MCNP-4C code and available experimental results. Ann. Nucl. Energy 53, 529-534. https://doi.org/ 10.1016/j.anucene.2012.09.015.

Tijani, S.A., Al-Hadeethi, Y. The use of isophthalic-bismuth polymer composites as radiation shielding barriers in nuclear medicine. Mater. Res. Express 6, 055323 https://doi.org/10.1088/2053-1591/ab0578.

Wozniak, A.I., Ivanov, V.S., Zhdanovich, O.A., Nazarov, V.I., Yegorov, A.S., 2017. Modern approaches to polymer materials protecting from ionizing radiation. Orient. J. Chem. 33 (5), 2148-2163. https://doi.org/10.13005/ojc/330502.

Wündrich, K., 1977. A review of radiation resistance for plastic and elastomeric materials. Radiat. Phys. Chem. 24, 503-510. https://doi.org/10.1016/0146-5724 (84)90185-7.

Yasmin, S., Barua, B.S., Khandaker, M.U., Rashid, M.A., Bradley, D.A., Olatunji, M.A., Kamal, M., 2018. Studies of ionizing radiation shielding effectiveness of silica-based commercial glasses used in Bangladeshi dwellings. Results Phys. 9, 541-549. https://doi.org/10.1016/j.rinp.2018.02.075.

Yastrebinsky, R.N., Pavlenko, V.I., Matyukhin, P.V., Chetverikov, N.A., 2011. Composite material for protection against gamma radiation. Bulletin of BSTU named after V.G. Shukhov. 6, 17-20.

Yastrebinsky, R.N., Pavlenko, V.I., Matukhin, P.V., Cherkashina, N.I., Kuprieva, O.V., 2013. Modifying the surface of iron-oxide minerals with organic and inorganic modifiers. Middle East J. Sci. Res. 18 (10), 1455-1462. 